\title{
Diagnostic Value of NT-proBNP and Left Ventricular Filling Pressure in Chronic Kidney Disease (CKD) Patients with Acute Decompensated Heart Failure
}

Abeera Mansur ( $\square$ abeeramansur@hotmail.com )

Doctors Hospital and Medical Centre, Lahore

Syeda Huma Zartash

Doctors Hospital and Medical Centre, Lahore

Zain Rasool

Doctors Hospital and Medical Centre, Lahore

Shahbaz Sarwar

Doctors Hospital and Medical Centre, Lahore

Nimra Nadeem

Doctors Hospital and Medical Centre, Lahore

Sidra Saleem

Doctors Hospital and Medical Centre, Lahore

\section{Research Article}

Keywords: NT-proBNP, Acute Decompensated Heart Failure, Chronic Kidney Disease

Posted Date: October 25th, 2021

DOI: https://doi.org/10.21203/rs.3.rs-987950/v1

License: (9) (i) This work is licensed under a Creative Commons Attribution 4.0 International License.

Read Full License 


\section{Abstract}

\section{Background}

The diagnosis of Acute Decompensated Heart Failure (ADHF) in Chronic Kidney Disease(CKD) patients is complex, NT-pro BNP interpretation in such a setting is complicated. The aim of this study is to determine the cutoff for NT-proBNP in CKD patients with ADHF.

Methods: In this retrospective, cross-sectional study, 85 hospitalized patients were evaluated, 66 had CKD. All patients had clinical evidence of volume overload. NT-proBNP and eGFR were assessed in all patients. Left Ventricular Filling Pressure (LVFP) was measured to confirm the diagnosis of ADHF.

Results: NT-proBNP was higher in volume overloaded patients with age more than 75 years as compared to those less than 75 years. NT-proBNP was higher in patients with CKD compared to non CKD patients. NT-proBNP progressively increased according to the CKD stage.

The cutoff of NT- proBNP in patients with clinical evidence of volume overload and CKD was $1750 \mathrm{pg} / \mathrm{ml}$ and $2760 \mathrm{pg} / \mathrm{ml}$ in patients with high LVFP. In CKD patients with clinical volume overload and a high LVFP the NT-proBNP cutoff value was $3737 \mathrm{pg} / \mathrm{ml}$.

There was a positive correlation of NT-BNP with LVFP and diastolic dysfunction.

Conclusion: NT-proBNP has utility for the diagnosis of ADHF. It is higher in the CKD population and rises progressively with CKD stages. The cutoff for the diagnosis of ADHF in CKD patients is $3737 \mathrm{pg} / \mathrm{ml}$ in the setting of confirmed evidence of ADHF with a high LVFP.

\section{Introduction}

Chronic Kidney Disease (CKD) and Heart Failure (HF) are common conditions. CKD prevalence is as high as $15 \%$ in the US (37 million people of the adult population). ${ }^{1}$

Globally there are 850 million individuals with CKD and around 64.3 million individuals with heart failure. $^{2}$

CKD and HF are both chronic diseases and share many risk factors such as diabetes mellitus, advanced age, hypertension and coronary artery disease.

$27.7 \%$ of all CKD patients have HF. The prevalence of HF in patients $>66$ years increases with the CKD stage, $21.5 \%$ in CKD 1-2, 28.4\% in CKD 3, 41.3\% in CKD 4-5. HF, has been found to be almost four times as common relative to patients without CKD. ${ }^{3}$

Additionally, amongst HF patients, 30 to 60 percent have moderate to severe kidney impairment. ${ }^{4}$ 
Survival is also affected with the presence of both conditions. It has been shown that CKD is associated with increased mortality in HF patients. ${ }^{5}$

A report by United States Renal Data System (USRDS) shows that the probability of survival in patients > 66 years, with HF and CKD Stage 4-5 is 0.512 at 24 months compared to 0.669 in patients with no CKD. ${ }^{3}$

Worsening HF is often associated with $\mathrm{AKI}$ and such patients have an increased risk for mortality and hospitalization.

The severity of AKI was also associated with greater mortality. ${ }^{6}$

In a patient with suspected acute decompensated heart failure(ADHF), the approach includes history and physical examination. The diagnosis of ADHF in CKD patients can be challenging. Oftentimes symptoms and physical examination alone are not enough and studies have shown that the assessment of volume needs additional measures in order to establish a diagnosis and help in assessing the prognosis.

It is imperative to identify the optimal volume status of patients and adjust medical management accordingly.

Plasma concentrations of natriuretic peptides like B-type Natriuretic peptide (BNP) and N-terminal pro-Btype natriuretic peptide (NT-proBNP) is helpful in making a diagnosis of ADHF. Distension of the cardiac ventricle stimulates the release of pro hormone pro BNP which is split into the active BNP and the inactive NT-proBNP. Measurement of NT-proBNP has been recommended for the evaluation of patients with ADHF by the American College of Cardiology guidelines in 2013, the 2010 Heart Failure Society of America guidelines and the 2012 European Society of Cardiology guidelines.

BNP and NT-proBNP may have comparable diagnostic and prognostic accuracy. $7,8,9,10$

Kidney Disease: Improving Global Outcomes (KDIGO) Controversies Conference held in 2019 recommended the measurement of BNP or N-terminal pro-B-type natriuretic peptide for the evaluation of dyspnea in CKD patients. The use of these markers was added to assist in the clinical decision-making regarding the diagnosis of $A D H F$, especially where the clinical scenario is confusing and uncertain. ${ }^{11}$

It has been ascertained that using the current cutoffs for HF there is low correlation between BNP and NTproBNP. This was seen in particular in the CKD population. The ratio of NT BNP to BNP increased with worsening estimated glomerular filtration rate (eGFR). The ratio of NT-proBNP to BNP in CKD Stage V was much higher compared to patients with eGFR $>60 \mathrm{~mL} / \mathrm{min} / 1.73 \mathrm{~m}^{2}$. (17 vs 4.7$){ }^{12}$

CKD Stage V patients had a much higher ratio of NT-proBNP to BNP than patients with eGFR $>60$ $\mathrm{mL} / \mathrm{min} / 1.73 \mathrm{~m}^{2}$ (17.0 vs. 4.7$) .^{12}$

The potential of NT-proBNP to diagnose ADHF in CKD patients remains challenging since normal cut off levels were obtained in patients without CKD. 
There may be diminished renal clearance of NT-proBNP. NT-proBNP levels were shown to be higher in the CKD patients than in the non CKD ones. ${ }^{13,} 14$

1256 patients with acute dyspnea were evaluated in the International Collaborative of NT-proBNP (ICON) study. They found that a NT-proBNP cutoff of $900 \mathrm{pg} / \mathrm{mL}$ had almost similar diagnostic accuracy as a BNP of $100 \mathrm{pg} / \mathrm{mL} .^{15}$

In the PARADIGM-HF trial (Prospective Comparison of ARNI With ACEI to Determine Impact on Global Mortality and Morbidity in Heart Failure), the ratio of NT-proBNP to BNP was 6.25:1 in patients with a low Ejection Fraction (EF), which is higher than previous guidelines. However, this study was not done in patients with ADHF but rather in those who were in New York Heart Association functional class II to IV with a left ventricular ejection fraction (LVEF) $\leq 40 \% .{ }^{16}$

BNP cutoff values for the diagnosis of ADHF in heart failure with reduced ejection fraction (LVEF $<40 \%$ ) HFrEF were higher than those in heart failure with preserved ejection fraction (LVEF $>50 \%$ )HFpEF across CKD stages $3-4 .{ }^{17}$

Therefore, the diagnosis of volume overload using natriuretic peptides is complicated as age, EF and CKD can influence the levels in addition to obesity, gender, sepsis, pulmonary hypertension and hepatic dysfunction.

In CKD patients, use of Echocardiography can help in establishing a diagnosis of ADHF by providing additional information on ventricular systolic function, wall thickness, valve function, chamber volumes and filling pressures. In addition, grades of diastolic dysfunction (grades 1-4 - American Society of Echocardiography) can be assessed. Use of Echocardiography has been recommended by the Kidney Disease: Improving Global Outcomes (KDIGO) Controversies Conference titled Heart Failure in CKD to aid in establishing a diagnosis of ADHF. ${ }^{10,11}$

\section{Aim:}

The aim of this study is to establish a relationship and a cutoff value for NT-pro BNP in CKD patients for the diagnosis of Acute Decompensated Heart Failure(ADHF).

Elevated Left ventricular filling pressures (LVFP) is also a well-known indicator of poor prognosis and is elevated in ADHF. The relationship of NT pro-BNP with LVFP in CKD patients is not well documented. Therefore, we wish to find integrative utility of measuring NT-proBNP levels with LVFP in patients with acute dyspnea enabling their utilization as diagnostic and prognostic markers in the management of CKD patients with ADHF.

\section{Methods}


This was a retrospective, cross sectional study approved by the Institutional Review Board and all methods were carried out in accordance with relevant guidelines and regulations. Charts of 450 patients who presented in the Emergency Department and who were admitted between 1st May, 2018 through 30th April, 2019, with acute dyspnea and potential ADHF were reviewed. Of these, 85 patients who had simultaneous echocardiography, NT-pro BNP measurement and who had evidence of clinical volume overload (pulmonary edema, pleural effusion, peripheral edema, raised JVP and response to diuretics) were included in the study. Informed consent was obtained from these patients for their evaluation and management and included 2D Echo, NT-BNP and eGFR/serum creatinine. Data such as physician notes, laboratory results and diagnostic imaging was reviewed through medical records. Both CKD (66) and non CKD (19) patients with reduced LV ejection fraction (LVEF <40\%: HFrEF), Midrange (LV EF:40-50\%:

$\mathrm{HFmrEF}$ ) and preserved ejection fraction (LVEF $>50 \%$ : HFpEF) were included. eGFR was measured using the Chronic Kidney Disease- Epidemiology (CKD-Epi) equation and was classified according to the KDIGO guidelines and defined as abnormalities of kidney structure or function, present for 3 months, with implications for health.

GFR category GFR $\left(\mathrm{ml} / \mathrm{min}\right.$ per $\left.1.73 \mathrm{~m}^{2}\right)$

CKD Stage I $<=90$

Stage II $\quad 60-89$

Stage III $\quad 30-59$

Stage IV $\quad 15-29$

Stage V $\quad<15$

NT-proBNP was measured by using a commercially available assay, Elecsys ProBNP II, that utilizes two monoclonal antibodies to recognize epitopes located in the $\mathrm{N}$ - terminal part of proBNP.

Echocardiography was used to assess diastolic function, left ventricular filling pressure, LVFP and ejection fraction

According to 2016 Diastology Guidelines, the following echocardiographic parameters of LV diastolic dysfunction and their abnormal cutoff values were used:

1. e'(e'sep $<7 \mathrm{~cm} / \mathrm{sec}$ or e'lat $<10 \mathrm{~cm} / \mathrm{s})$

2. E/e' average ratio $(>14)$

3. Left Atrial Volume index $\left(>34 \mathrm{ml} / \mathrm{m}^{2}\right)$ 
LV diastolic dysfunction is present if more than half of the available parameters meet these cutoff values. 18

LV filling pressures was determined as elevated if either $E / A$ ratio was $\geq 2$ in the presence of myocardial disease, or if $E / A$ was $<2$, with $E$ velocity of $>50 \mathrm{~cm} / \mathrm{s}$ and at least 2 of the 3 parameters (ratio of mitral peak $\mathrm{E}$ velocity to average annular velocity- E/e'ratio of $>14$, peak tricuspid regurgitation velocity of $>2.8$ $\mathrm{m} / \mathrm{sec}$ and left atrial maximal volume index of $>34 \mathrm{~mL} / \mathrm{m} 2$ ) were above cutoff.

The same algorithm was applied in patients with depressed left ventricular ejection fraction (LVEF) or normal LVEF but with myocardial disease. E/A ratio of $<$ or $=0.8$ was considered normal LVFP. ${ }^{18}$

The E/e' ratio should not be used to measure LVFP in subjects with significant mitral annular calcification (MAC). However, mitral E/A ratio and Isovolumic Relaxation Time (IVRT) are useful predictors of LVFP in these patients. The proposed algorithm combining these Doppler parameters is reliable in estimating LVFP in patients with MAC. ${ }^{19}$ We had only two patients with moderate MAC, however these patients fulfilled the criteria for an elevated LVFP as assessed by IVRT (<80msec).

\section{Statistical Analysis:}

Data were stored and analyzed using IBM-SPSS version 23.0. Mean with Standard deviation were reported for quantitative data sets, counts with percentages were given for qualitative outcomes. Mean comparison of NT-proBNP was done using one-way ANOVA with age group, CKD stages, HF(EF) and combined group of patients with clinical volume overload, high LV filling pressure, CKD and age of patients. Independent sample t-test was used to compare NT-proBNP in CKD and non CKD patients. Spearman rank correlation analysis was done to see the relationship of NT-proBNP with LV filling pressure, diastolic dysfunction and EF. Receiver operating curve (ROC) analysis was constructed to find area under the curve, sensitivity and specificity of NT-proBNP in patients with CKD and high LVFPs. Cutoff values of NT-proBNP were also estimated using ROC. P-values less than 0.05 were considered statistically significant.

\section{Results}

Table 1 depicts the baseline characteristic of the studied patients. In the present study there were eightyfive patients with mean age $64.70(S D= \pm 13.93)$ years. Majority (69) patients were less than 75 years (81.2\%). 16 patients were more than 75 years (18.8 percent). There were $50.6 \%$ males and $49.4 \%$ females, $51.7 \%$ hypertensive, $52.9 \%$ diabetic, $55.3 \%$ had an increased LV filling pressure, all patients were clinically volume overload and $77.6 \%$ had CKD with a mean GFR of $32.06, \mathrm{SD}= \pm 14.5 \mathrm{ml} / \mathrm{min} / 1.73 \mathrm{~m}^{2}$.

Amongst the Non- CKD patients 7 had an EF of $<40 \%, 1$ had an EF of $40-50 \%$ and 11 had an EF of $>50 \%$. 
24 CKD patients had an EF of $<24 \%, 9$ had an EF of $40-50 \%$ and 33 had an EF of $>50 \%$.

Table 1

Baseline Characteristics of Studied Samples $(n=85)$

\begin{tabular}{|c|c|c|c|c|c|}
\hline Characteristics & & CKD & Non- CKD & $\mathbf{n}$ & $\%$ \\
\hline \multirow[t]{3}{*}{ Age group } & $\leq 75$ Years & 51 & 18 & 69 & 81.2 \\
\hline & $\geq 75$ Years & \multirow[t]{2}{*}{15} & \multirow[t]{2}{*}{1} & 16 & 18.8 \\
\hline & $\operatorname{Mean}( \pm S D)$ & & & 64.70 & \pm 13.93 \\
\hline \multirow[t]{2}{*}{ Gender } & Male & 33 & 10 & 43 & 50.6 \\
\hline & Female & 33 & 9 & 42 & 49.4 \\
\hline Hypertension & Present & 37 & 7 & 44 & 51.7 \\
\hline Diabetes Mellitus & Present & 39 & 6 & 45 & 52.9 \\
\hline \multirow[t]{2}{*}{ LV Filling Pressure } & Normal & 30 & 8 & 38 & 44.7 \\
\hline & Increased & 36 & 11 & 47 & 55.3 \\
\hline \multirow[t]{3}{*}{ EF } & $<40 \%$ & $24(36.4 \%)$ & $7(36.8 \%)$ & & \\
\hline & $40-50 \%$ & $9(13.6 \%)$ & $1(5.26 \%)$ & & \\
\hline & $>50 \%$ & $33(50 \%)$ & $11(57.89 \%)$ & & \\
\hline Fluid Overload & Present & 66 & 19 & 85 & 100 \\
\hline \multirow[t]{2}{*}{ GFR $\mathrm{ml} / \mathrm{min} / 1.73 \mathrm{~m}^{2}$} & \multicolumn{3}{|c|}{ Non CKD 84.3 \pm 17.8} & 19 & 22.4 \\
\hline & \multicolumn{3}{|c|}{ CKD $32.06 \pm 14.5$} & 66 & 77.6 \\
\hline
\end{tabular}

Table-2 reports the mean comparison of NT-proBNP $(\mathrm{pg} / \mathrm{ml})$. Results showed that patients with clinical evidence of volume overload, high LVFP, CKD and age under 75-years had NT-proBNP values (Mean $=13480.37, \mathrm{SD}= \pm 12679.9)$ as compared to samples of age more than 75-years old having a non statistically higher NT-proBNP $(p g / m l)(M e a n=20876.22, S D= \pm 14862.12)(p=0.15)$.

All patients more than 75-years old had a statistically higher NT-proBNP(pg/ml) (Mean $=17701.87$, $S D= \pm 13854.83$ ) as compared with patients with age less than 75 years (Mean 7754.8, $S D= \pm 10939.6$ ) $(p=0.014)$.

The mean NT-pro BNP of CKD patients was much higher than the non CKD patients. CKD patients had a NT-proBNP of $11649.47, S D= \pm 12854.51)$ non CKD patients had a NT-proBNP value of 2602.46 (SD= $\pm 4436.89)(p<0.01)$.

There was a progressive increase in BNP value with worsening renal function $(p<0.01)$. 
However, there was no significant mean difference in NT-proBNP with respect to gender $(p=0.18)$.

Table-3 gives the correlation of NT-proBNP with LVFP, Diastolic dysfunction and EF. Results showed a significant positive correlation of NT-proBNP with LVFP $(r=0.30: p=0.01)$, Diastolic dysfunction $(r=0.35$ : $p=0.01)$ and significant negative correlation with $E F(r=-0.40: p<0.01)$.

Table 4 shows the mean NT-proBNP(pg/ml) in Non CKD vs CKD clinically volume overloaded patients. CKD patients with a high LVFP had a mean NT-proBNP of $15329.33, S D \pm 13434$ ( $p$ 0.009). Non CKD patients with a high LVFP had a mean BNP of $3935.78, S D \pm 5522.77$. Non CKD patients with a normal LVFP had a mean BNP of 769.15, SD \pm 643.04. CKD patients with a normal LVFP had a mean BNP of $7233.63 \mathrm{SD} \pm 10750.24(\mathrm{p}=0.001)$.

A receiver operating characteristic curve, $\mathrm{ROC}$ analysis with high LVFP suggested that the area under the curve was $67.7 \%$, with sensitivity $63.8 \%$ and specificity $64 \%$, the cut-off value of NT-proBNP was observed $2760 \mathrm{pg} / \mathrm{ml}$ for high LVFP patients with CKD and clinical evidence of volume overload, $p<0.005$. Figure 1 and Table 5.

A receiver operating characteristic curve, $\mathrm{ROC}$ analysis with CKD suggested that the area under the curve was $79 \%$, with sensitivity $69.7 \%$ and specificity $69 \%$, the cut-off value of BNP was $1750 \mathrm{pg} . \mathrm{ml}$ for CKD samples, $p<0.01$. Figure 2 and Table 6.

A receiver operating characteristic curve, $(\mathrm{ROC})$ analysis with the CKD, high LVFP and clinical volume overload suggested that the area under the curve was $77 \%$, with sensitivity $69 \%$ and specificity $70 \%$, the cut-off value of NT-proBNP was $3737 \mathrm{pg} / \mathrm{ml}$. Figure 3 and Table 7.

Figure 4: shows a comparison of Mean NT-proBNP in Non CKD vs CKD patients with ADHF and a high LVFP and shows that the mean NT-proBNP in CKD patients with ADHF is much higher than in Non CKD patients. $(p=0.009)$ 
Table 2

Mean Comparison of NT-proBNP with Studied Parameters

\begin{tabular}{|c|c|c|c|c|}
\hline & $\mathbf{N}$ & Mean & SD & p-value \\
\hline \multicolumn{5}{|l|}{ Groups } \\
\hline Group-1 & 27 & 13480.37 & 12679.90 & \multirow[t]{4}{*}{0.15} \\
\hline \multicolumn{4}{|c|}{ ADHF+high LVFP+CKD+ Age $\leq 75$} & \\
\hline Group-2 & 9 & 20876.22 & 14862.12 & \\
\hline \multicolumn{4}{|c|}{ ADHF+LVFP+CKD+ Age $>75$} & \\
\hline \multicolumn{5}{|l|}{ Age Group } \\
\hline$<=75$ years & 69 & 7754.80 & 10939.60 & \multirow[t]{2}{*}{$0.014^{*}$} \\
\hline$>75$ years & 16 & 17701.87 & 13854.83 & \\
\hline \multicolumn{5}{|l|}{ CKD } \\
\hline No & 19 & 2602.46 & 4436.89 & \multirow[t]{2}{*}{$<0.01 *$} \\
\hline Yes & 66 & 11649.47 & 12854.51 & \\
\hline \multicolumn{5}{|l|}{ CKD Stages } \\
\hline NONE & 19 & 2602.46 & 4436.89 & \multirow[t]{5}{*}{$<0.01 *$} \\
\hline $3 A .45-59$ & 15 & 6460.67 & 10898.06 & \\
\hline 3B.30-44 & 24 & 9063.33 & 9253.00 & \\
\hline STAGE4 & 13 & 8626.38 & 12081.38 & \\
\hline STAGE5 & 14 & 24449.43 & 13530.87 & \\
\hline \multicolumn{5}{|l|}{ Gender } \\
\hline Female & 42 & 11397.10 & 13122.53 & \multirow[t]{2}{*}{0.18} \\
\hline Male & 43 & 7898.45 & 10891.28 & \\
\hline \multicolumn{4}{|l|}{ EF } & \multirow[t]{4}{*}{0.002} \\
\hline$<40 \%$ & 24 & 19865.29 & 13982.48 & \\
\hline $40-50 \%$ & 9 & 8064 & 2948.6 & \\
\hline$>50 \%$ & 33 & 6651.9 & 9775.53 & \\
\hline
\end{tabular}


Table 3

Correlation of BNP with Studied Parameters

\begin{tabular}{|lll|}
\hline Parameters & r-value & p-value \\
\hline LV Filling Pressure & 0.305 & $<0.01^{\star}$ \\
\hline DIASTOLIC.DYSFUNC & 0.356 & $<0.01^{\star}$ \\
\hline EF & -0.403 & $<0.01^{\star}$ \\
\hline$* \mathrm{p}<0.05$ was considered statistically significant for correlation \\
\hline
\end{tabular}

Table 4

Mean NT-proBNP in Non- CKD vs CKD clinically volume overloaded patients

\begin{tabular}{|lllll|}
\hline & $\begin{array}{l}\text { Non CKD + high } \\
\text { LVFP }\end{array}$ & CKD + high LVFP & $\begin{array}{l}\text { Non CKD + } \\
\text { normal LVFP }\end{array}$ & CKD +normal LVFP \\
\hline $\begin{array}{l}\text { Mean NT- } \\
\text { proBNP(pg/ml) }\end{array}$ & $3935.78 \pm 5522.77$ & $\begin{array}{l}15329.33 S D 13434 \\
(\mathrm{p} \mathrm{0.009).}\end{array}$ & $\begin{array}{l}769.15 \pm \\
643.04\end{array}$ & $\begin{array}{l}7233.63 S D 10750.24 \\
(\mathrm{p}=0.001)\end{array}$ \\
\hline
\end{tabular}

Table 5

ROC with high LVFP

\begin{tabular}{|llllll|}
\hline Area Under the Curve & $95 \% \mathrm{Cl}$ & P-value & Sensitivity & Specificity & NT-proBNP pg/ml \\
\hline 0.677 & $0.56-0.79$ & $<0.005$ & $63.8 \%$ & $64 \%$ & 2760 \\
\hline
\end{tabular}

Table 6

ROC with CKD

\begin{tabular}{|llllll|}
\hline Area Under the Curve & $95 \% \mathrm{Cl}$ & P-value & Sensitivity & Specificity & NT-proBNP pg/ml \\
\hline 0.79 & $0.68-0.9$ & $<0.01$ & $69.7 \%$ & $69 \%$ & 1750 \\
\hline
\end{tabular}


Table 7

ROC for CKD with High LVFP \& Volume Overload

\begin{tabular}{|llllll|}
\hline Area Under the Curve & $\mathbf{9 5 \%}$ C.I & p-value & Sensitivity & Specificity & NT-proBNP pg/ml \\
\hline 0.77 & $0.67-0.86$ & $<0.01 *$ & $69 \%$ & $70 \%$ & 3737 \\
\hline
\end{tabular}

\section{Discussion}

Normal BNP and NT-proBNP are more helpful to rule out heart failure rather than ruling it in. ${ }^{20}$ This was demonstrated in CKD patients as well in a study of 142 euvolemic patients. Median NT-proBNP and BNP levels were found to be 59 and $311 \mathrm{pg} / \mathrm{ml}$, respectively. ${ }^{21}$

To rule out ADHF, the values of these markers were determined in 142 euvolemic patients with GFR 38 $\mathrm{SD} 14 \mathrm{ml} / \mathrm{min}$ per $1.73 \mathrm{~m}^{2}$. In another study of 151 patients a NT-proBNP cutoff value of $<1000 \mathrm{pg} / \mathrm{mL}$ was used to ascertain that patients were no longer volume overloaded and to decrease the diuretic dose in patients with acute kidney injury. These patients had lower cardiovascular event rates. ${ }^{22}$

There are many variables that influence the levels of BNP and NT-proBNP.

In one study NT- proBNP levels were studied in different age groups. The suggested cutoff of NT-proBNP $450 \mathrm{pg} / \mathrm{mL}$ for $<50$ years of age, $900 \mathrm{pg} / \mathrm{mL}$ for $50-75$ years and $1,800 \mathrm{pg} / \mathrm{mL}$ for $>75$ years gave $90 \%$ sensitivity and $84 \%$ specificity for acute HF. ${ }^{17}$

We also found that the older patients $>75$ years had higher NT BNP values. However in the $>75$ years CKD population with $A D H F$, there was no statistically significant difference, although the mean values were much higher.

There have been many studies that have looked at the relationship of BNP and NT-proBNP in the setting of CKD for the diagnosis of ADHF. Although it has been suggested that a higher cut-off value of BNP and NT-proBNP for diagnosis of HF be used, the absolute values remain debatable.

In the Breathing Not Properly study, in patients with an eGFI of less than $60 \mathrm{~mL} / \mathrm{min}$, a BNP cutoff of less than $200 \mathrm{pg} / \mathrm{mL}$ was suggested to rule-out HF. ${ }^{23}$

Using a cut point of $1,200 \mathrm{pg} / \mathrm{ml}$ of NT pro-BNP for subjects with GFR<60 ml/min/1.73 m2, a study evaluating 599 patients found sensitivity to be $89 \%$ and specificity to be $72 \%{ }^{24}$

In a meta- analysis of 9 studies with 4,287 patients, NT-proBNP was higher in CKD patients with ADHF as compared to non CKD individuals. The median cut off point was $1,980 \mathrm{pg} / \mathrm{ml}^{25}$ 
In another study on patients with a mean GFR of $27.7 \pm 14 \mathrm{ml} / \mathrm{min} / 1.73 \mathrm{~m}^{2}$, NT-proBNP cutoff for the diagnosis of ADHF in patients with an EF of $42.9 \pm 6.8 \%$ was $4502 \mathrm{pg} / \mathrm{ml} . .{ }^{26}$

We showed that the cutoff for CKD patients for NT-proBNP was $1750 \mathrm{pg} / \mathrm{ml}$.

Plasma BNP and NT-proBNP concentrations were shown to be increased with declining renal function. This was demonstrated in a study of 213 patients with CKD. Since NT-proBNP clearance may be predominantly renal, it was shown that a declining GFR had a greater effect on plasma NT-proBNP than on BNP.

Mean BNP concentration increased by $20.6 \%$ for every $10-\mathrm{mL} / \mathrm{min} / 1.73 \mathrm{~m} 2(0.17-\mathrm{mL} / \mathrm{s})$ decline in eGFR. Whereas there was a $37.7 \%$ increase in NT-proBNP. NT-proBNP/BNP ratio was also shown to increase with CKD stage. ${ }^{27}$

In another study of 381 patients, presenting with dyspnea to the emergency room, NT BNP and BNP values were determined. NT-proBNP and BNP cut-off points rose with deteriorating GFR: from 1360 and $290 \mathrm{pg} / \mathrm{ml}$ in patients with eGFR $60-89 \mathrm{ml} / \mathrm{min} / 1.73 \mathrm{~m} 2$, to 6550 and $515 \mathrm{pg} / \mathrm{ml}$ in patients CKD Stage $4 .^{28}$

We also had similar findings of progressive increase in NT-proBNP with worsening GFR.

We had ascertained our patients to be in ADHF on clinical grounds, however the use of 2D Echo and elevated left ventricular filling pressure (LVFP) may be used to make a definitive diagnosis of ADHF and improve diagnostic accuracy when used in addition to clinical parameters.

Echocardiography non-invasively identifies the presence of increased LV filling pressures. ${ }^{29}$

Use of both natriuretic peptides and echocardiography can be used to confirm

heart failure and provide risk stratification across all stages of heart failure and in particular diagnose heart failure when BNP or NT-proBNP levels fall in the intermediate or "grey" zone. ${ }^{30}$

In a study of 116 patients hospitalized with ADHF, simultaneous BNP and 2D echo using E/Ea (reflecting LVFP) had an incremental predictive power for the outcome of cardiac death or readmission for ADHF had an incremental predictive power for the outcome of cardiac death or readmission for ADHF. ${ }^{31}$

It has been shown that an elevated BNP level along with an E/e' ratio >15 (part of the assessment of LVFP) has the greatest risk of mortality in the setting of an acute myocardial infarction. ${ }^{32}$

Better HF clinical outcomes have been shown when BNP-guided management and ultrasound (lung US and LV filling pressure) are used. ${ }^{33}$ 
Another retrospective research found that combining BNP and LVFP resulted in improved survival and a lower incidence of acute kidney injury. ${ }^{34}$

Thus, a position paper has recommended the use of BNP and LVFP in the management of HF patients in the ambulatory setting. ${ }^{35}$

NT-proBNP also correlated strongly with indices of LVFP in a study of sixty-eight symptomatic patients with isolated diastolic dysfunction. ${ }^{36}$

We also had a similar finding of positive correlation.

The NT-proBNP cutoff for patients with a high LVFP was $2760 \mathrm{pg} / \mathrm{ml}$.

The range of NT Pro BNP values to rule in volume overload has been put forth and is between 1000-6550 $\mathrm{pg} / \mathrm{ml}$.

The cutoff value for NT-proBNP in our study for CKD patients was $1750 \mathrm{pg} / \mathrm{ml}$ and the cutoff in patients with high LVFP was $2760 \mathrm{pg} / \mathrm{ml}$. We showed that when ROC was generated for patients with CKD, clinical volume overload and with a high LVFP, a cut off value of $3737 \mathrm{pg} / \mathrm{ml}$ was obtained. Sensitivity and specificity were $69 \%$ and $70 \%$ respectively with AUC of 0.77 .

Thus, ADHF can be ruled in by using a cutoff of $3787 \mathrm{pg} / \mathrm{ml}$ of NT-proBNP and a high LVFP.

The cut off of $3787 \mathrm{pg} / \mathrm{ml}$ may be more reliable as a cutoff for the diagnosis of ADHF as the clinical scenario of volume overload has been verified with a high LVFP. This cutoff value of NT-proBNP in patients with a high LVFP could help in confirmation of ADHF and help in patient management.

Our cutoff was higher than many papers. This could be explained by the fact that the mean GFR in our patient population was lower $\left(32.06 \mathrm{ml} / \mathrm{min} / 1.73 \mathrm{~m}^{2}\right)$ than in previous studies and that half the patients had an EF of $<55 \%$. Using a high LVFP also leads to a higher cutoff.

The mean NT-proBNP values were also higher than in previous studies. Our mean value of NT BNP was higher than the cutoff value as our data was skewed.

NT-proBNP has also been strongly associated with severity of diastolic dysfunction, with diastolic dysfunction being identified in one out of every four patients with elevated NT pro BNP. ${ }^{37}$

Although it did not function well as a screening test for diastolic dysfunction in a cross-sectional analysis from the Chronic Renal Insufficiency Cohort (CRIC) Study, the highest quartile of NT-proBNP was associated with two-fold odds of diastolic dysfunction in the CKD population compared with the lowest quartile in a cross-sectional analysis from the Chronic Renal Insufficiency Cohort (CRIC) Study. ${ }^{38}$

We have also found a positive correlation of diastolic dysfunction with NT BNP. 
NT BNP value has been shown to be higher in patients with lower ejection fraction. ${ }^{39}$

We found a negative correlation of NT BNP with EF. This has been shown in CKD 3-4 patients in whom there was a higher BNP cutoff value for the diagnosis of ADHF in HFrEF as compared to the patients with HFpEF with CKD stages $3-4 .{ }^{17}$

In another study of stable ischemic heart disease patients BNP and NT BNP showed a negative correlation to LVEF $(r=-0.50$ and -0.46$) .{ }^{40}$

\section{Conclusions}

NT pro-BNP is a rapid and reliable marker for accurate and early diagnosis of ADHF. The cutoff value of NT Pro BNP for diagnosis of ADHF in CKD is higher than in the non CKD population and progressively increases as the stage of CKD increases. To obtain optimal results, cut off concentrations have to be adjusted for renal function.

NT-proBNP has a significant relationship with LVFP and Diastolic dysfunction in CKD patients with ADHF. Use of NT-proBNP and a high LVFP in CKD patients in the setting of ADHF can aid in making a definitive diagnosis of ADHF. We found that a higher than previously reported cutoff of NT-proBNP should be used,

\section{Limitations}

We had a small sample size and this was a retrospective study. We did not adjust NT-proBNP for weight, pulmonary, neurologic and hepatic comorbidities. We did not have follow up evaluation of NT pro BNP and Echocardiogram and were not able to monitor changes with treatment. We did not have correlation of NT-proBNP with New York Heart Association Stages. Our data was skewed resulting in a higher mean value as compared to the cutoff. Because of the small sample size, we were not able to analyze the NTpro BNP value in the different stages of CKD patients according to the heart failure subtype (HFpEF vs. HFrEF).

\section{Declarations}

\section{Ethics Approval and Consent to participate}

Ethical approval was taken from the Ethical review board committee at Doctors Hospital and Medical Center, Lahore, Pakistan. All methods were carried out in accordance with relevant guidelines and regulations. There were no experimental protocols.

All patients gave informed consent for their evaluation and management that included 2D Echo, NT-pro BNP, serum creatinine. 


\section{Consent for publication}

"Not applicable"

\section{Availability of data and materials}

The datasets used and/or analyzed during the current study are available from the corresponding author.

\section{Competing interests}

"The authors declare that they have no competing interests"

\section{Funding}

'No external funding'

\section{Author's Contributions}

1. AM has made substantial contribution in the conception and design of the study, data acquisition, data preparation and presentation, statistical interpretation of data, research coordination and management, drafting of manuscript, revising and editing the manuscript critically for important intellectual contents.AM has approved the submitted version.

2. SHZ has made substantial contribution in conception and design of study, research coordination, acquisition and interpretation of data and data collection. SHZ has approved the submitted version.

3. ZR has made substantial contribution in acquisition and interpretation of data. ZR has approved the submitted version.

4. SS has made substantial contribution to the conception and design of study, performing 2D echoes, editing the manuscript critically. SS has approved the submitted version.

5. NN has made substantial contribution in data collection. NN has approved the submitted version.

6. SS has made substantial contribution conception and design of study, in acquisition and interpretation of data, revising and editing the manuscript critically for important intellectual contents. SS has approved the submitted version.

\section{Acknowledgements}




\section{Authors Information:}

Abeera Mansur, MD, FACP, FASN, Diplomate American Board of Internal Medicine and Nephrology

Syeda Huma Zartash, MRCP

Zain Rasool, MBBS

Shahbaz Sarwar, Dip Card

Nimra Nadeem, MBBS

Sidra Saleem, FCPS Nephrology

All authors are affiliated with Doctors Hospital and Medical Center Lahore, Pakistan

\section{References}

1. Centers for Disease Control and Prevention. Chronic Kidney Disease in the United States, 2021. Atlanta, GA: US Department of Health and Human Services, Centers for Disease Control and Prevention; 2021.

2. GBD 2017 Disease and Injury Incidence and Prevalence Collaborators. Global, regional, and national incidence, prevalence, and years lived with disability for 354 diseases and injuries for 195 countries and territories, 1990-2017: a systematic analysis for the Global Burden of Disease Study 2017. Lancet 2018; 392:1789-1858.

3. Robinson SR, Abbott KC et al. US Renal Data System 2019 Annual Data Report: epidemiology of kidney disease in the United States. Am J Kidney Dis. 2020;75(1) (suppl 1) A6-A7. USRDS ANNUAL REPORT

4. Smith GL, Lichtman JH, Bracken MB, Shlipak MG, Phillips CO, DiCapua P, Krumholz HM. Renal impairment and outcomes in heart failure: systematic review and meta-analysis. J Am Coll Cardiol. 2006;47(10):1987. Epub 2006 Apr 24.

5. Fonarow GC, Adams KF Jr, Abraham WT, Yancy CW, Boscardin WJ. Risk stratification for in-hospital mortality in acutely decompensated heart failure: classification and regression tree analysis. ADHERE Scientific Advisory Committee, Study Group, and Investigators. JAMA. 2005;293(5):572.

6. Damman K, Navis G, Voors AA, Asselbergs FW, Smilde TD, Cleland JG, van Veldhuisen DJ, Hillege HL Worsening renal function and prognosis in heart failure: systematic review and meta-analysis. $J$ Card Fail. 2007;13(8):599.

7. Mueller C, McDonald K, de Boer RA, Maisel A, Cleland JGF, Kozhuharov N, Coats AJS, Metra M, Mebazaa A, Ruschitzka F, Lainscak M, Filippatos G, Seferovic PM, Meijers WC, Bayes-Genis A, 
Mueller T, Richards M, Januzzi JL Jr; Heart Failure Association of the European Society of Cardiology. Heart Failure Association of the European Society of Cardiology practical guidance on the use of natriuretic peptide concentrations. Eur J Heart Fail. 2019 Jun;21(6):715-731

8. Yancy CW, Jessup M, Bozkurt B, et al, American College of Cardiology Foundation/American Heart Association Task Force on Practice Guidelines. 2013 ACCF/AHA guideline for the management of heart failure: a report of the American College of Cardiology Foundation/American Heart Association Task Force on practice guidelines. Circulation. 2013 Oct 15. 128(16):e240-327.

9. Lindenfeld J, Albert NM, Boehmer JP, et al. For the Heart Failure Society of America. HFSA 2010 comprehensive heart failure practice guideline. J Card Fail. 2010 Jun. 16(6): e1-194.

10. Ponikowski P, Voors AA, Anker SD, et al.For the Authors/Task Force Members. 2016 ESC guidelines for the diagnosis and treatment of acute and chronic heart failure: The task force for the diagnosis and treatment of acute and chronic heart failure of the European Society of Cardiology (ESC). Developed with the special contribution of the Heart Failure Association (HFA) of the ESC. Eur Heart J. 2016 Jul 14. 37 (27):2129-200.

11. House AA, Wanner C, Sarnak MJ, Piña IL, Mclntyre CW, Komenda P, Kasiske BL, Deswal A, deFilippi CR, Cleland JGF, Anker SD, Herzog CA, Cheung M, Wheeler DC, Winkelmayer WC, McCullough PA; Conference Participants. Heart failure in chronic kidney disease: conclusions from a Kidney Disease: Improving Global Outcomes (KDIGO) Controversies Conference. Kidney Int. 2019 Jun;95(6):13041317. Epub 2019 Apr 30.

12. Farnsworth CW, Bailey AL, Jaffe AS, Scott MG. Diagnostic concordance between nt-probnp and bnp for suspected heart failure. Clin Biochem 2018; 59:50-5.

13. Colbert G, Jain N, de Lemos JA, Hedayati SS. Utility of traditional circulating and imaging-based cardiac biomarkers in patients with predialysis CKD. Clin J Am Soc Nephrol. 2015 Mar 6;10(3):51529.

14. Mueller C, Laule-Kilian K, Scholer A, Nusbaumer C, Zeller T, Staub D, Perruchoud AP. B-type natriuretic peptide for acute dyspnea in patients with kidney disease: insights from a randomized comparison. Kidney Int. 2005;67(1):278.

15. Januzzi JL, van Kimmenade R, Lainchbury J, Bayes-Genis A, Ordonez-Llanos J, Santalo-Bel M et al. NT-proBNP testing for diagnosis and short-term prognosis in acute destabilized heart failure: an international pooled analysis of 1256 patients: The International Collaborative of NT-proBNP Study, European Heart Journal, Volume 27, Issue 3, February 2006, 330-337

16. Rørth R, Jhund PS, Yilmaz MB, Kristensen SL, WelshP, Desai AS,Køber L et al, Comparison of BNP and NT-proBNP in Patients With Heart Failure and Reduced Ejection Fraction. Circulation: Heart Failure. 2020;13

17. Kadri AN, Kaw R, Al-Khadra Y, et al. The role of B-type natriuretic peptide in diagnosing acute decompensated heart failure in chronic kidney disease patients. Arch Med Sci. 2018;14(5):10031009. 
18. Nagueh SF, Smiseth OA, Appleton CP, Byrd BF 3rd, Dokainish H, Edvardsen T, Flachskampf FA, Gillebert TC, Klein AL, Lancellotti P, Marino P, Oh JK, Popescu BA, Waggoner AD. Recommendations for the Evaluation of Left Ventricular Diastolic Function by Echocardiography: An Update from the American Society of Echocardiography and the European Association of Cardiovascular Imaging. J Am Soc Echocardiogr. 2016 Apr;29(4):277-314.

19. Abudiab MM,Chebrolu LH, Schutt RC, Nagueh SF, Zoghbi: WA.Doppler Echocardiography for the Estimation of LV Filling Pressure in Patients With Mitral Annular Calcification. JAC: Cardiovascular Imaging; Volume 10, Issue 12, December 2017, Pages 1411-1420

20. Hill, SA, Booth, RA, Santaguida, PL. et al. Use of BNP and NT-proBNP for the diagnosis of heart failure in the emergency department: a systematic review of the evidence. Heart Fail Rev 19, 421-438 (2014)

21. Tagore R, Ling LH, Yang H, Daw HY, Chan YH, Sethi SK. Natriuretic peptides in chronic kidney disease. Clin J Am Soc Nephrol. 2008 Nov;3(6):1644-51. Epub 2008 Jul 16.

22. Ibrahim NE, Gaggin HK, Rabideau DJ, Gandhi PU, Mallick A, Januzzi JL Jr. Worsening Renal Function during Management for Chronic Heart Failure with Reduced Ejection Fraction: Results From the ProBNP Outpatient Tailored Chronic Heart Failure Therapy (PROTECT) Study. J Card Fail. 2017 Feb;23(2):121-130.

23. McCullough PA, Duc P, Omland T, et al. B-type natriuretic peptide and renal function in the diagnosis of heart failure: an analysis from the Breathing Not Properly Multinational Study. Am J Kidney Dis. 2003 Mar. 41(3):571-9.

24. Anwaruddin S, Lloyd-Jones DM, Baggish A, Chen A, Krauser D, Tung R, Chae C, Januzzi JL Jr. Renal function, congestive heart failure, and amino-terminal pro-brain natriuretic peptide measurement: results from the ProBNP Investigation of Dyspnea in the Emergency Department (PRIDE) Study. J Am Coll Cardiol. 2006;47(1):91. Epub 2005 Dec 9

25. Schaub JA, Coca SG, Moledina DG, Gentry M, Testani JM, Parikh CR. Amino-Terminal Pro-B-Type Natriuretic Peptide for Diagnosis and Prognosis in Patients With Renal Dysfunction: A Systematic Review and Meta-Analysis. JACC Heart Fail. 2015;3(12):977-989.

26. Jafri L, Kashif W, Tai J,Siddiqui I, Azam I, Shahzad H, Ghani F. B-type natriuretic peptide versus amino terminal pro-B type natriuretic peptide: selecting the optimal heart failure marker in patients with impaired kidney function. BMC Nephrology 2013, 14:117

27. Vickery S, Price CP, John RI, Abbas NA, Webb MC, Kempson ME, Lamb EJ. B-type natriuretic peptide (BNP) and amino-terminal proBNP in patients with CKD: relationship to renal function and left ventricular hypertrophy. Am J Kidney Dis. 2005 Oct;46(4):610-20.

28. Chenevier-Gobeaux $C$, Claessens $Y E$, Voyer $S$, et al. Influence of renal function on N-terminal pro-brain natriuretic peptide (NT-proBNP) in patients admitted for dyspnoea in the Emergency Department: comparison with brain natriuretic peptide (BNP). Clin Chim Acta. 2005 Nov. 361(1-2):167-75

29. Andersen OS, Smiseth OA, Dokainish H, Abudiab MM, Schutt RC, Kumar A, Sato K, Harb S, Gude E, Remme EW, Andreassen AK, Ha JW, Xu J, Klein AL, Nagueh SF. Estimating Left Ventricular Filling 
Pressure by Echocardiography. J Am Coll Cardiol. 2017 Apr 18;69(15):1937-1948.

30. Troughton RW, Richards AM. B-Type Natriuretic Peptides and Echocardiographic Measures of Cardiac Structure and Function, JACC: Cardiovascular Imaging,Volume 2, Issue 2,2009,Pages 216225

31. Dokainish H, Zoghbi WA, Lakkis NM, Ambriz E, Patel R, Quinones MA, Nagueh SF. Incremental predictive power of B-type natriuretic peptide and tissue Doppler echocardiography in the prognosis of patients with congestive heart failure, Journal of the American College of Cardiology,Volume 45, Issue 8,2005,Pages 1223-1226.

32. Kruszewski K, Scott AE, Barclay JL, Small GR, Croal BL, Møller JE, Oh JK, Hillis GS. Noninvasive assessment of left ventricular filling pressure after acute myocardial infarction: a prospective study of the relative prognostic utility of clinical assessment, echocardiography, and B-type natriuretic peptide. Am Heart J. 2010 Jan;159(1):47-54.

33. Bajraktari G, Pugliese NR, D'Agostino A, Rosa GM, Ibrahimi P, Perçuku L, Miccoli M, Galeotti GG, Fabiani I, Pedrinelli R, Henein M, Dini FL. Echo- and B-Type Natriuretic Peptide-Guided Follow-Up versus Symptom-Guided Follow-Up: Comparison of the Outcome in Ambulatory Heart Failure Patients. Cardiol Res Pract. 2018 Sep

34. Simioniuc A, Carluccio E, Ghio S, et al. Echo and natriuretic peptide guided therapy improves outcome and reduces worsening renal function in systolic heart failure: An observational study of 1137 outpatients. Int J Cardiol. 2016; 224:416-423.

35. Dini FL, Carluccio E, Montecucco F, Rosa GM, Fontanive P. Combining echo and natriuretic peptides to guide heart failure care in the outpatient setting: A position paper. Eur J Clin Invest. 2017 Dec;47(12). Epub 2017 Nov 14.

36. Tschöpe C, Kasner M, Westermann D, Gaub R, Poller WC, Schultheiss HP. Eur Heart J. 2005;26(21):2277. Epub 2005 Jul 13. The role of NT-proBNP in the diagnostics of isolated diastolic dysfunction: correlation with echocardiographic and invasive measurements.

37. McGrady M, Reid CM, Shiel L, Wolfe R, Boffa U, Liew D, Campbell DJ, Prior D, Krum H. N-terminal Btype natriuretic peptide and the association with left ventricular diastolic function in a population at high risk of incident heart failure: results of the SCReening Evaluationof the Evolution of New-Heart Failure Study (SCREEN-HF). Eur J Heart Fail. 2013 May;15(5):573-80. doi: 10.1093/eurjhf/hft001. Epub 2013 Jan 20.

38. Mishra RK, Li Y, Ricardo AC, Yang W, Keane M, Cuevas M, Christenson R, deFilippi C, Chen J, He J, Kallem RR, Raj DS, Schelling JR, Wright J, Go AS, Shlipak MG. Chronic Renal Insufficiency Cohort Investigators (2013). Association of N-terminal pro-B-type natriuretic peptide with left ventricular structure and function in chronic kidney disease (from the Chronic Renal Insufficiency Cohort [CRIC]). The American journal of cardiology, 111(3), 432-438.

39. Belagavi AC, Rao M, Pillai AY, Srihari US. Correlation between NT proBNP and left ventricular ejection fraction in elderly patients presenting to the emergency department with dyspnoea. Indian Heart J. 2012;64(3):302-304 
40. Richards M, Nicholls MG, Espiner EA, Lainchbury JG, Troughton RW, Elliott J, Frampton CM, Crozier IG, Yandle TG, Doughty R, MacMahon S, Sharpe N, Christchurch Cardioendocrine Research Group, Australia-New Zealand Heart Failure Group. Comparison of B-type natriuretic peptides for assessment of cardiac function and prognosis in stable ischemic heart disease. J Am Coll Cardiol. 2006;47(1):52. Epub 2005 Dec 15.

\section{Figures}

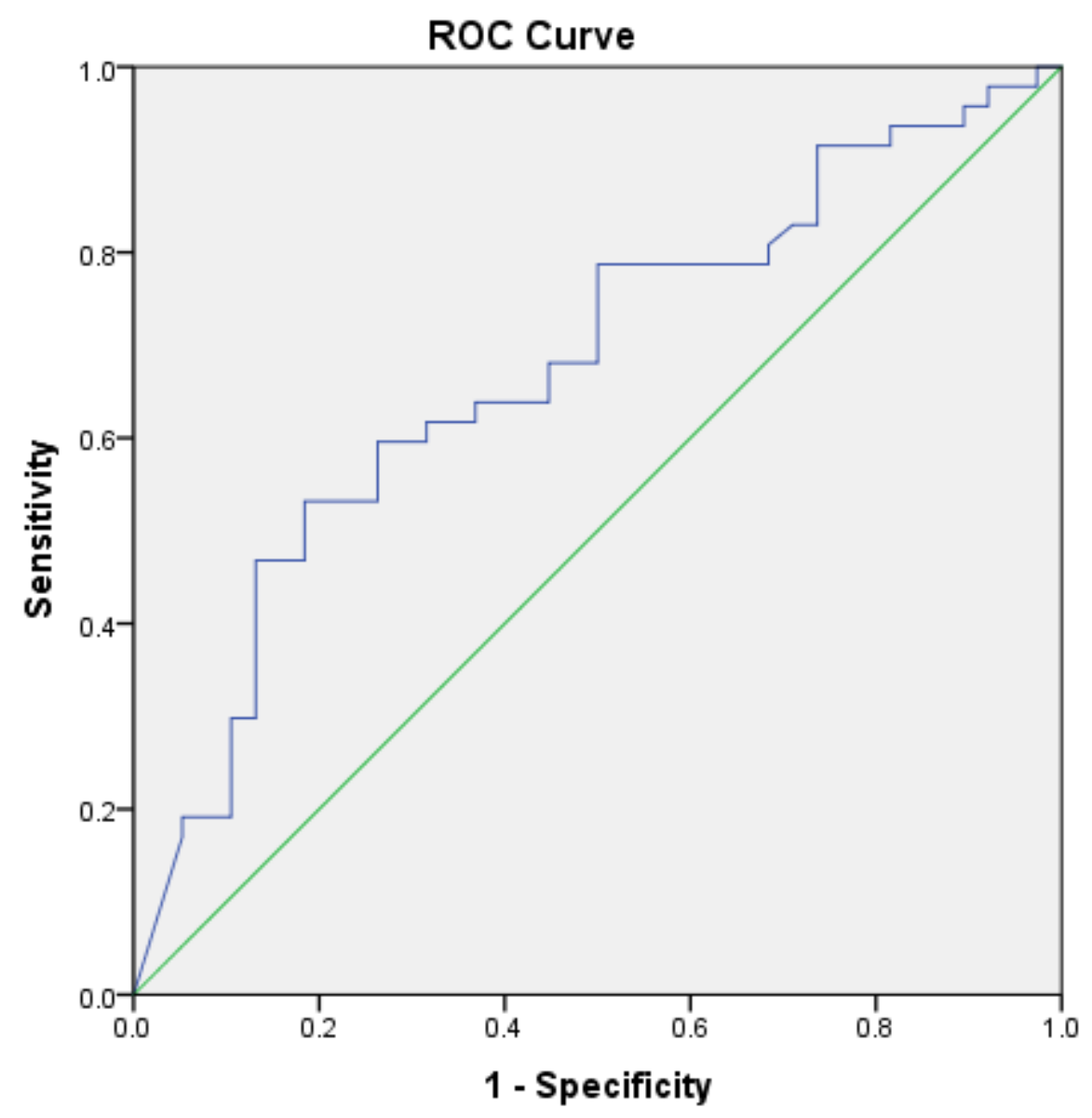

Figure 1

ROC curve with high LVFP 


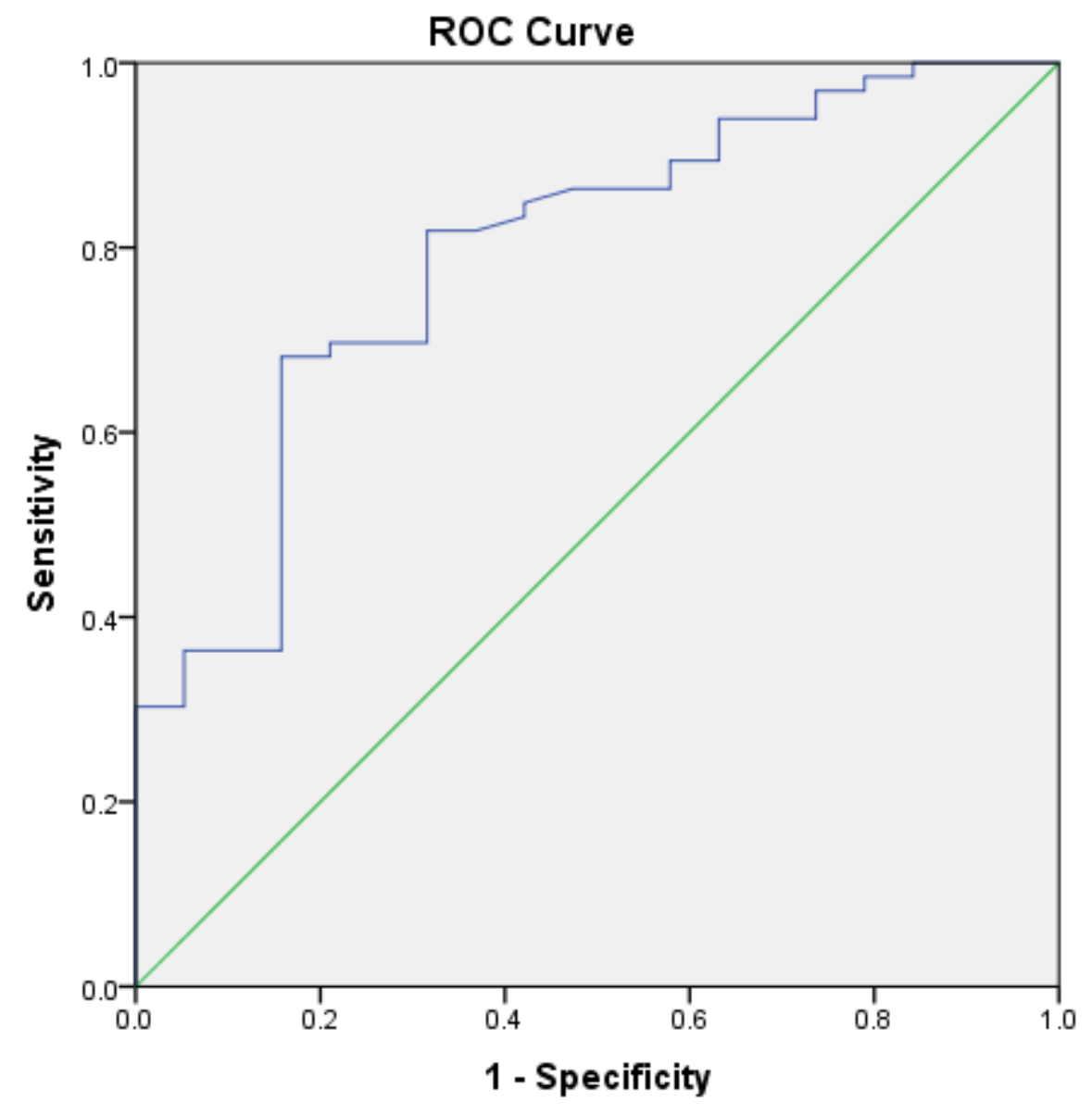

Figure 2

ROC curve with CKD 


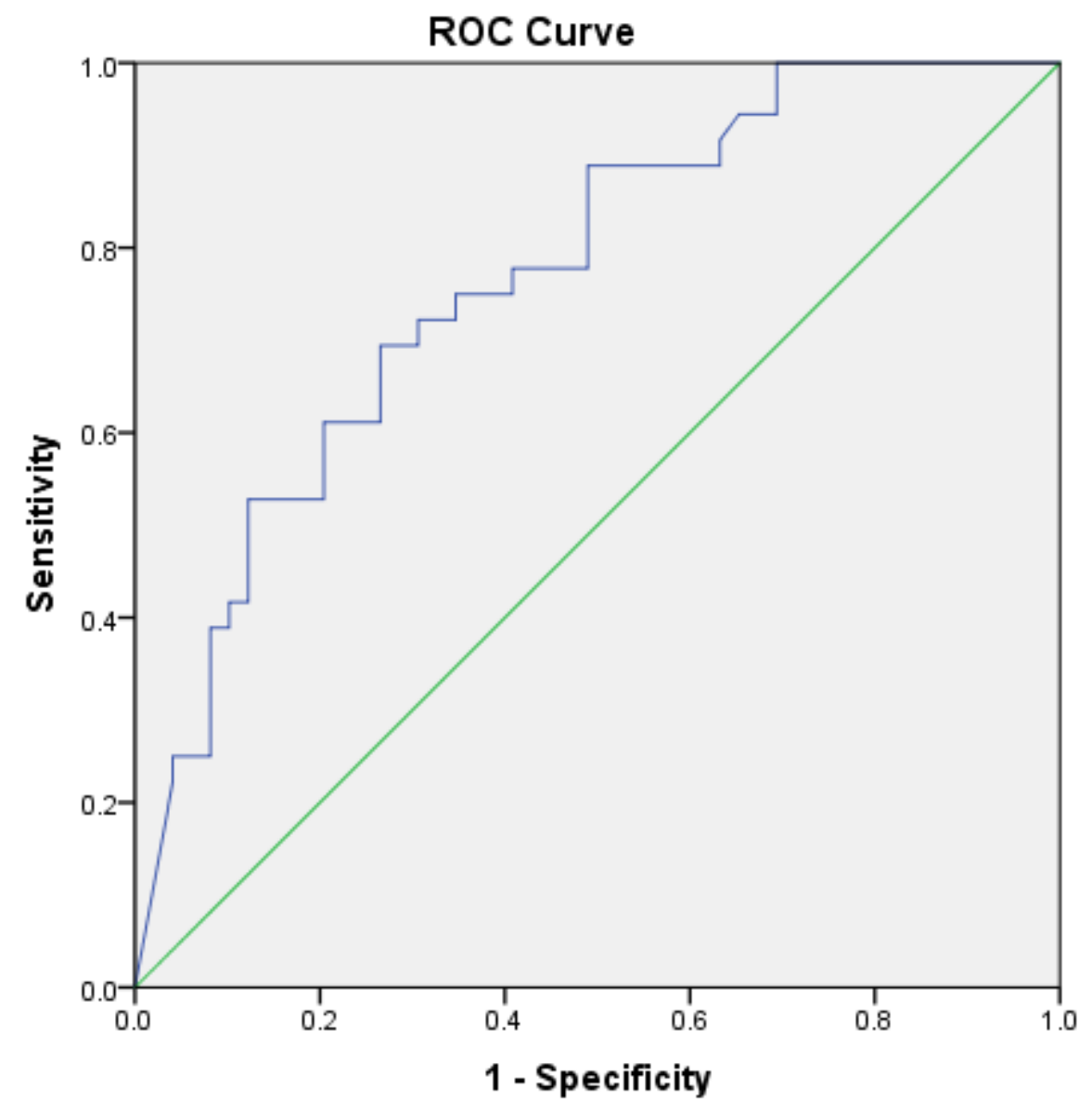

Figure 3

ROC for CKD with High LVFP \& Volume Overload. 


\section{NT pro BNP in ADHF patients with high LVFP}

20000

Mean

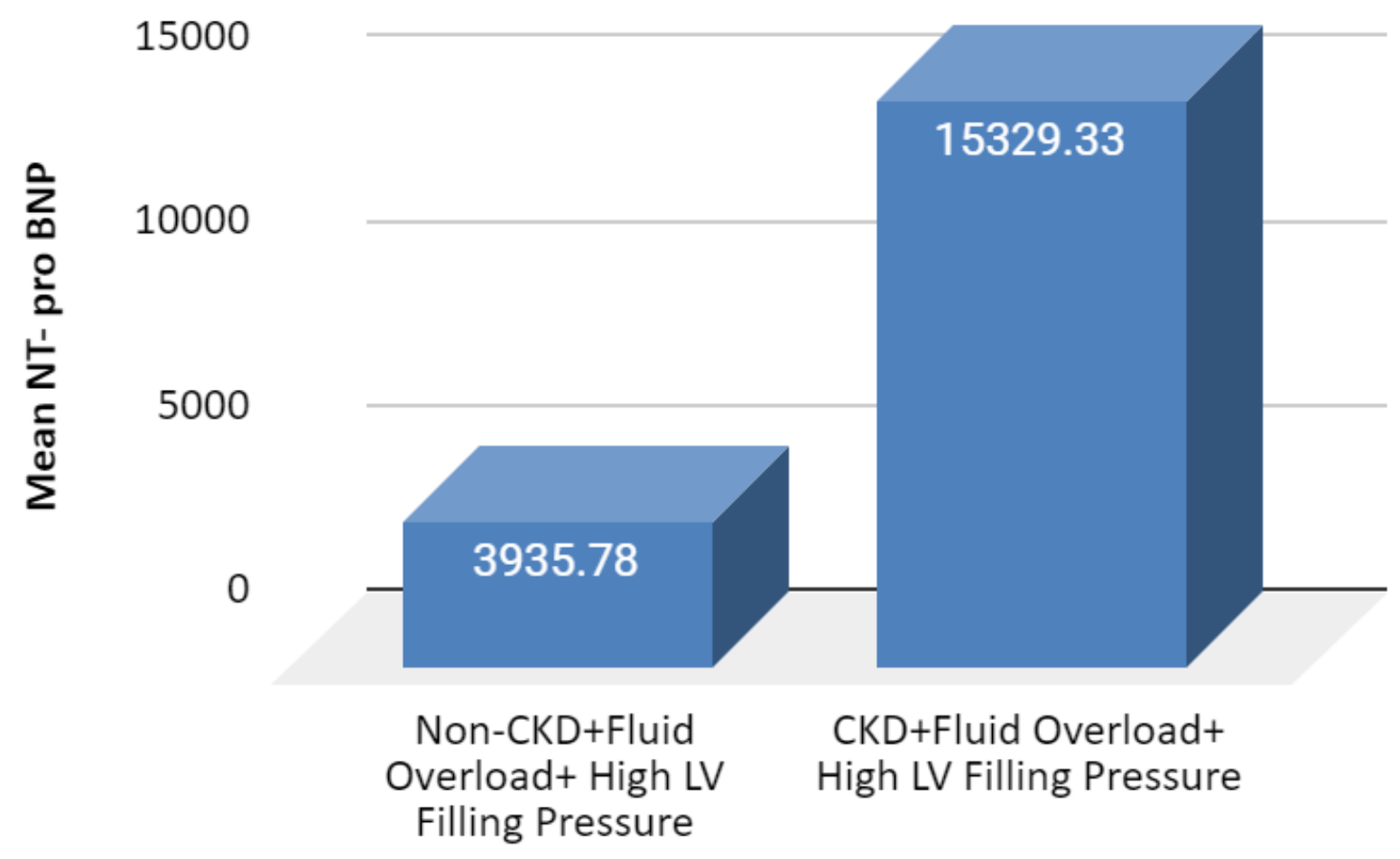

Figure 4

Comparison of Mean NT-proBNP in Non CKD vs CKD patients with ADHF and a high LVFP 